\title{
O Uso da Comunicação Aumentativa e Alternativa para Apoiar o Diálogo de Pessoas com Deficiência Intelectual
}

\section{Andrei Carniel ${ }^{1}$, Carla Diacui Medeiros Berkenbrock ${ }^{1}$, Tiago Anunciação Ricaldi $^{1}$, Simone Erbs da Costa ${ }^{1}$ and Aliciene Fusca Machado Cordeiro ${ }^{2}$}

\author{
${ }^{1}$ Universidade do Estado de Santa Catarina - UDESC and ${ }^{2}$ Universidade da Região de Joinville - UNIVILLE \\ *andrei.carniel@gmail.com; carla.berkenbrock@udesc.br; tiagoricaldi@hotmail.com; simoneerbsdacosta@gmail.com; \\ aliciene_machado@hotmail.com
}

Submetido: 29/11/2017. Revisado: 23/03/2018. Aceito: 15/04/2018.

\begin{abstract}
Resumo
A Comunicação Aumentativa e Alternativa é uma das estratégias para lidar com problemas de comunicação, especialmente para pessoas com a deficiência intelectual (DI). A Comunicação Aumentativa e Alternativa explora mais de um canal de comunicação para enviar mensagens, mas não garante que a comunicação aconteça. Assim este trabalho tem como objetivo identificar como ocorre a comunicação para as pessoas com DI, bem como desenvolver um sistema de Comunicação Aumentativa e Alternativa para apoiar a comunicação dessas pessoas. Para estudar a solução desse problema, este trabalho utiliza o Design Science Research (DSR), Design Participativo e análise qualitativa. O Design Participativo é utilizado em três ciclos do DSR. Os ciclos são realizados da seguinte forma: conhecimento sobre o usuário; adaptação de um modelo de comunicação; desenvolvimento do protótipo de telas; e desenvolvimento do sistema de Comunicação Aumentativa e Alternativa. Esta pesquisa foi realizada com uma pessoa com paralisia cerebral, apraxia e sem discurso funcional. Como resultados obtidos destaca-se: os requisitos do sistema de comunicação para pessoas com deficiência intelectual, os protótipos de tela, a implementação do sistema, e a realização da análise qualitativa do uso da Comunicação Aumentativa e Alternativa.
\end{abstract}

Palavras-Chave: Comunicação aumentativa e alternativa; deficiência intelectual; design participativo.

\begin{abstract}
The Augmentative and Alternative Communication is one of the strategies to deal with communication problems, especially for people with intellectual disabilities. Augmentative and Alternative Communication exploits more than one communication channel to send messages, but it does not guarantee that communication will happen. Thus this work aims to identify how communication occurs for people with intellectual disabilities as well as to develop an Augmentative and Alternative Communication system to support the communication of these people. To study the solution of this problem, this work uses the Design Science Research (DSR), Participatory Design and qualitative analysis. Participatory Design is used in three cycles of DSR. The cycles are performed as follows: knowledge about the user; adaptation of a communication model; the development of prototype screens; and the development of the Augmentative and Alternative Communication system. This research was performed with a person with cerebral palsy, apraxia and without functional speech. This work presents as results: the requirements of the communication system for people with intellectual disabilities, the screen prototypes, the implementation of the system, and the qualitative analysis of the use of Augmentative and Alternative Communication.
\end{abstract}

Key words: Augmentative and alternative Communication; intellectual disability; participatory design. 


\section{Introdução}

A comunicação, seja ela por meio de fala, escrita, por gestos ou imagens, é a principal forma de transmissão de conhecimentos. A deficiência na comunicação pode comprometer a interação, compreensão, aprendizado, bem como compartilhamento de ideias e sentimentos (Moreschi and Almeida; 2012). A dificuldade de comunicação pode impedir pessoas de manifestarem uma ideia ou necessidade, e em casos extremos, de participarem da sociedade. Nesses casos, não há uma solução única para fazer com que a comunicação ocorra (Tomas et al.; 2016). Dentre as pessoas com alguma deficiência na comunicação, pode-se citar pessoas com Deficiência Intelectual (DI), Síndrome de Down ou Autismo. É importante destacar que ainda há a possibilidade dessas pessoas apresentarem outras dificuldades, tais como: problemas cognitivos, memória verbal pobre e dificuldade de aprendizado (Falcão and Price; 2012).

A Comunicação Aumentativa e Alternativa (CAA) é uma forma de comunicação para auxiliar pessoas sem fala ou escrita funcional, ou em defasagem na sua habilidade de falar ou escrever (Melo; 2014). Essa forma de comunicação não se restringe a apenas um canal de comunicação (Wheeler et al.; 2013). A CAA permite a combinação de vários tipos de comunicação como: expressões faciais, expressões corporais, uso de gestos, sons, imagens, textos, entre outras (Huijbregts and Wallace; 2015). A CAA também pode trabalhar em conjunto com dispositivos de alta tecnologia que podem servir como um meio de mediação da comunicação (Carniel et al.; 2017). Essa mediação da comunicação gera uma informação que permite que "pessoas que vivem, por exemplo, à margem da sociedade, sejam provocadas pela apropriação e empoderamento da informação, propiciando o surgimento da consciência do valor que estas pessoas têm sobre suas vidas" (Farias; 2016), além de gerar uma inclusão social dessas pessoas na sociedade por meio da alta tecnologia. Assim, "o uso das Tecnologias de Informação e Comunicação pode ser visto como um importante fator para a inclusão social, e a potencialidade de inclusão é ainda mais relevante para grupos de pessoas que enfrentam condições de vida limitadoras" (Caran et al.; 2016).

A CAA pode ser utilizada com a alta tecnologia, a qual caracteriza-se por utilizar dispositivos eletrônicos, dentre eles: notebooks, vocalizadores e dispositivos móveis (tais como smartphones e tablets) (Moreschi and Almeida; 2012). Dentre eles, os dispositivos móveis são considerados os mais intuitivos (Bonifácio et al.; 2010), portáteis e causam menos distração durante seu uso (Black et al.; 2012). Além disso, eles integram várias tecnologias de comunicação como WiFi, Bluetooth e 4G (Still et al.; 2015). Destaca-se que uso de tecnologias para comunicação é uma das áreas que mais crescem na sociedade (Pinheiro and Neris; 2013), dessa forma, este trabalho almeja explorar em como os dispositivos móveis podem ser utilizados com a CAA, e seu potencial para apoiar a comunicação de pessoas com deficiência intelectual. Para a condução desta pesquisa é utilizada a metodologia Design Science Research (DSR) (Hevner; 2007) em conjunto com Design Participativo (DP) (Rogers et al.; 2007). Uma das características do DSR é ter o foco voltado para o conhecimento de como um determinado resultado foi obtido, considerando que providenciar um conhecimento claro das definições, limites, ontologias, resultados de concepção e execução, são vitais para uma comunidade científica. A relevância do problema, os ciclos de design e o rigor (como foram feitas a avaliação e documentação) devem estar documentados no DSR. O DSR contribui para melhorar uma teoria ou construir uma nova, por meio de uma série de inovações ou análises de artefatos, para gerar e documentar conhecimento em uma determinada área.

O DP utilizado durante os ciclos de design do DSR é uma técnica de design que se caracteriza por incluir profissionais e usuários finais de uma determinada área, durante a etapa de desenvolvimento do projeto (Rocha and Baranauskas; 2003). O DP considera os usuários finais como membros ativos, os quais atuam fornecendo contribuições e considerações importantes para o desenvolvimento do projeto. Com base nessas metodologias o desenvolvimento de uma aplicação de CAA utilizando dispositivos móveis foi implementada para apoiar a comunicação de pessoas com deficiência intelectual. Neste deste artigo o objetivo é identificar como ocorre a comunicação para pessoas que possuem DI, bem como suas necessidades.

\section{Deficiência Intelectual}

Deficiência Mental ou Deficiência Intelectual (DI) é caracterizada por uma redução de compreensão de informações novas ou complexas, e na capacidade de aplicar esse conhecimento. Inicia-se antes da idade adulta e se prolonga pelo resto da vida. Pessoas com essa deficiência se caracterizam por possuir um QI menor que 70 pontos, e ela afeta de $2 \%$ a $3 \%$ da população (Reis; 2016). De acordo com a CID-11 (ASSOCIATION; 2014) o termo "diagnóstico deficiência intelectual", equivale ao diagnóstico da CID-11 de transtornos do desenvolvimento intelectual. A pessoa com Deficiência Intelectual deve apresentar 3 características: (I) Déficit nas atividades mentais genéricas, como: raciocínio, planejamento, solução de problemas, abstração, juízo e aprendizagem; (II) Déficits resultam em prejuízos no funcionamento adaptativo, como incapacidade de atingir padrões de independência e responsabilidade social; (III) Início dos déficits intelectuais e adaptativos durante o período de desenvolvimento. Seu diagnóstico avalia a compreensão combinada de 4 grupos de fatores etiológicos: biomédicos, comportamentais, sociais e educacionais (Carvalho and Maciel; 2003). DI não é uma diferença qualquer que possa ser incorporada na escola sem a compreensão adequada, mas também não deve ser compreendida como algo estigmatizante ou segregador. De fato, é uma realidade diferente, a pessoa com alguma deficiência tem suas particularidades, como: o tempo para realizar uma determinada atividade e forma de comunicação. Essas particularidades podem ter pouco, médio ou grande impacto na convivência da pessoa em questão com a sociedade. A categorização de uma pessoa com DI é um assunto delicado; uma vez que ele for classificado como tal, entrará numa espécie de destino predeterminado. De certa forma, 
categorizar é atribuir uma única justificativa para explicar uma série de dificuldades, sendo que algumas destas dificuldades poderiam ser superadas por meio da vivência adequação ao meio, ao invés apenas de tachar como "incapaz" (Mantoan; 1994).

\section{Trabalhos Correlatos}

Os trabalhos correlatos incluem os estudos que fundamentam ou apoiam o desenvolvimento do protótipo que emprega a CAA para as pessoas com deficiência. Black et al. (2012) realizam um estudo sobre a eficácia de gerar frases baseadas no dia a dia de cada pessoa, a fim de apoiar a interação de pessoas com deficiência em um diálogo. Waller et al. (2009) analisam como facilitar oportunidades de comunicação e interação, por meio de uso de um aplicativo para contar histórias e piadas para crianças com paralisia cerebral. Hong et al. (2014) realizam um estudo sobre a precisão de implantação do método de CAA para um adulto com Transtorno do Espectro Autista (TEA). No trabalho são analisadas as diferenças do uso da CAA em duas perspectivas: inicialmente sem a utilização das propostas de regras de CAA e após utilização da proposta de regras. Tania et al. (2014) testam a utilização de CAA para promover o desenvolvimento da linguagem em casa, escola e ambiente comunitários, para crianças com paralisia cerebral e TEA. Dentre os trabalhos mencionados, Black et al. (2012) destacam o uso colaboração em seu trabalho. Nele uma terapeuta é responsável por organizar as frases para auxiliar a comunicação de pessoas com paralisia cerebral. Estas frases são organizadas de acordo com informações coletadas no cotidiano do usuário, por meio de sensores e softwares. Já a proposta do presente trabalho, utiliza a CAA em uma estrutura de sujeito, ação e opção de ação. Além disso, profissionais, responsáveis e familiares colaboram para gerar uma CAA personalizada, de acordo com as necessidades e aptidões do usuário.

O trabalho de Black et al. (2012) relaciona-se com o presente trabalho por destacar uma abordagem utilizando o contexto do dia a dia, para apoiar a comunicação de pessoas com paralisia cerebral e pouca fala funcional. Já Waller et al. (2009) relacionase por utilizar uma aplicação para propiciar a comunicação de pessoas com paralisia cerebral com a comunidade, a fim de gerar diálogos mais interativos e facilitar a comunicação. Hong et al. (2014) também trabalha com pessoas sem fala funcional, bem como realiza o estudo de uma pessoa que já possuía uma forma de comunicação, neste caso, uma pasta com imagens de comunicação impressas. Por fim, Tania et al. (2014) relaciona-se por fornecer resultados de implementação de uma proposta de regras de utilização de CAA, bem como elementos necessários para utilização das regras.

\section{Aplicação da Metodologia DSR}

O DSR propõe a utilização de 3 ciclos: a relevância do problema, que identifica e delimita o ambiente de pesquisa, necessidades e oportunidades; o ciclo de design, que permite realizar a construção de teorias e artefatos, e testes destes; e o ciclo do rigor, que detalha formas de avaliação e resultados. O DP é usado em 3 iterações realizadas no ciclo de design. Dentre os métodos do DP, foram utilizados os métodos de workshop e de protótipos de alta fidelidade durante a realização do ciclo de design do DSR. Durante o design, cada etapa serviu de base para o desenvolvimento da próxima. Para este trabalho, tivemos a participação de um paciente, do sexo masculino, 10 anos de idade, possuindo paralisia cerebral, dispraxia e sem fala funcional; duas profissionais, uma terapeuta ocupacional e uma fonoaudióloga, responsáveis pelo atendimento do paciente na instituição onde é realizado o estudo; e a responsável do paciente, que é a mãe do paciente.

\subsection{Relevância do Problema}

Para iniciar o uso do DSR é necessário ter o conhecimento base, especificando o contexto de pesquisa, bem como as oportunidades, onde será realizada a pesquisa Hevner (2007). Para visualizar o escopo do problema a ser investigado, Hevner et al. (2004) disponibilizam um conjunto de diretrizes que o DSR deve apresentar. As diretrizes para este trabalho são apresentadas na Tabela 1.

A pessoa com deficiência de comunicação, independente de faixa etária, ainda que com esforço e tentativas sucessivas nem sempre está apta a se comunicar com o meio. A falta de compreensão da comunicação, além de prejudicar o convívio social, pode gerar sentimentos como angústia e agressividade, uma vez que essa pessoa sente a necessidade de se comunicar e não consegue. Além disso, a comunicação é essencial para o desenvolvimento social e aprendizado escolar de uma pessoa (Tania et al.; 2014). Neste contexto, este trabalho visa apoiar a comunicação da pessoa com DI, por meio do uso de dispositivos móveis e CAA, a fim de desenvolver uma comunicação de acordo com a necessidade do usuário. Dessa forma, um sistema onde profissionais e responsáveis colaboram para o desenvolvimento da CAA personalizada para o usuário é idealizado. O sistema de CAA busca propiciar uma forma de comunicação mais efetiva e próxima à realidade do usuário, facilitando na elaboração de frases e expressão de sua comunicação.

\subsection{Artefatos}

Para apoiar a comunicação de pessoas com DI, este trabalho tem o foco na elaboração de três artefatos sendo eles: (I) caracterização e descrição das necessidades de uma pessoa com DI; (II) um modelo de comunicação para pessoas com DI, baseado nas necessidades identificadas neste estudo, e com a finalidade de explicar como ocorre a comunicação para pessoa com DI; e (III) um aplicativo de CAA para dispositivos móveis, seguindo o padrão estabelecido no modelo de comunicação proposto. A elaboração dos artefatos foi realizada de forma incremental. Sendo os artefatos definidos como coisas e processos, incluindo pessoas, interfaces humano-computador, metodologia de projeto de sistemas e linguagens (Vaishnavi and Kuechler; 2004). 
Tabela 1: Diretrizes do DSR adaptado para a pesquisa.

Diretriz

Relevância do Problema

Aplicação da diretriz nessa pesquisa

A dificuldade de comunicação impede as pessoas de se comunicarem efetivamente, e nestes casos não há uma solução única para contornar a situação (Tomas et al.; 2016). A DI afeta de $2 \%$ a $3 \%$ da população, inicia antes da idade adulta e se prolonga pelo resto da vida (Reis; 2016). A presente pesquisa tem o foco em apoiar a comunicação de pessoa com DI, de forma a propiciar uma comunicação efetiva e novas oportunidades de comunicação.

\begin{tabular}{cc}
\hline Processo de Busca da Solução & $\begin{array}{c}\text { Seguindo as diretrizes do Design Science Research, utilizou-se o conceito de Design } \\
\text { Participativo da área de IHC, para pesquisa e desenvolvimento da solução. }\end{array}$ \\
\hline Design de Artefato & $\begin{array}{c}\text { Os artefatos produzidos são as telas para tablets, caracterização da pessoa com DI e o } \\
\text { modelo de comunicação para pessoa com DI. }\end{array}$ \\
\hline Avaliação & $\begin{array}{c}\text { A avaliação de usabilidade, com envolvimento do usuário, por meio da análise de } \\
\text { observação de uso em conjunto de especialistas. }\end{array}$ \\
\hline Rigor da Pesquisa & $\begin{array}{c}\text { Para cada ciclo do desenvolvimento da pesquisa foram utilizados um ou mais conceitos } \\
\text { para garantir o rigor da pesquisa. É utilizada avaliação de especialistas, workshops, } \\
\text { prototipação e análise de uso. }\end{array}$ \\
\hline Contribuições da Pesquisa & $\begin{array}{c}\text { Fortalecimento de Design Science Research em conjunto com Design Participativo; } \\
\text { Levantamento de requisitos para apoiar o uso de CAA em dispositivos móveis; Análise } \\
\text { do Design Participativo no processo de desenvolvimento; Análise do modelo de } \\
\text { comunicação para pessoas com DI. }\end{array}$ \\
\hline Comunicação da Pesquisa & $\begin{array}{c}\text { Comunidade científica interessada em desenvolvimento de sistemas que utilizem de } \\
\text { CAA em dispositivos móveis. }\end{array}$
\end{tabular}

Fonte: Elaborado pelo autor

\subsection{Ciclos de Design do DSR}

Foram realizados 3 ciclos de design do DSR, sendo: o primeiro ciclo destinado ao conhecimento do usuário, bem como sua descrição e caracterização das necessidades de comunicação. Após a realização deste ciclo foi gerada a teoria de que: a comunicação para pessoas com DI não ocorre da mesma forma que para pessoas que não possuam alguma deficiência, e sim por uma comunicação frequentemente apoiada na valorização de elementos específicos como gestos e imagens, para que se possa efetivar uma comunicação.

Com base na teoria de comunicação (primeiro ciclo e a pesquisa na literatura), foi gerado o artefato "Modelo de Comunicação", para utilização em um aplicativo por uma pessoa com DI, com a finalidade de efetivar uma comunicação; com uma proposta de modelo foram desenvolvidos os artefatos de "Protótipos de Telas", almejando uma interface minimalista, e priorizando os elementos descritos no modelo de comunicação proposto. Por fim, é apresentado o processo de criação da CAA para João por meio de workshops, são exibidos os resultados de implementação e é realizada uma análise qualitativa. Neste trabalho os workshops são utilizados em todos os ciclos de design; no ciclo 2, são usados protótipos de baixa fidelidade desenhados a papel e caneta; e no ciclo 3 utiliza-se protótipos de alta fidelidade.

\subsection{Ciclo 1 do Design - Problema de Comunicação}

Na primeira etapa do ciclo de design, foi realizado a coleta de dados inicial com uma instituição especializada em trabalhar com pessoas com deficiência intelectual e problemas de comunicação. A pesquisa consistiu de entrevistas em grupos e individuais, envolvendo as profissionais da instituição, um paciente e seu responsável. De acordo com relatos, a pessoa com DI, independente de faixa etária, nem sempre está apta a se comunicar, ainda que ela se esforce com tentativas sucessivas. A terapeuta relatou que o problema da falta de comunicação pode gerar sentimentos negativos, como a angústia, e algumas vezes a persistência deste problema pode desencadear atos agressivos. Outra situação relatada foi o chamado diálogo de convivência. Esse diálogo é caracterizado pela terapeuta ocupacional como um diálogo geralmente praticado no âmbito familiar, onde expressões como sons e gestos possuem significados. Embora seja uma forma de comunicação de fácil entendimento para as pessoas pertencentes ao meio, esse diálogo não se faz entendível a todas as pessoas, principalmente para aquelas que não interagem com a pessoa com DI. Muitas vezes a pessoa com DI quer se comunicar, sabe o que quer, mas não consegue colocar em palavras.

Para esta pesquisa trabalhamos com um paciente com paralisia cerebral, apraxia (disfunção motora neurológica que se caracteriza pela perda da capacidade de executar movimentos precisos) e dificuldade psicomotora elevada. Segundo a terapeuta e fonoaudióloga, o paciente gosta de escrever (ato que realiza somente por cópia, ele conhece as letras, porém não consegue formar as palavras), possui uma boa memória e senso de localização, não possui fala funcional, por vezes possui um comportamento desobediente (às vezes não aceita realizar as atividades) e algumas vezes possui comportamento agressivo. Após o início do acompanhamento com medicação controlada, o paciente teve melhoras na atenção e coordenação, e se tornou capaz de manter contato visual com pessoas. Embora tenha deficiência psicomotora, o paciente consegue utilizar smartphones, sabe jogar e consegue compreender os objetivos do jogo. Ressaltase que durante a realização dos workshops, esse padrão de comportamento relatado pela terapeuta e fonoaudióloga foi de fato o padrão constatado.

Para facilitar a comunicação, os pais e a terapeuta 
criaram seu próprio sistema de comunicação por imagens (ou do inglês Picture Communication System PCS), o qual consiste em uma pasta com imagens impressas. Esta pasta é constituída com figuras selecionadas na internet, e organizadas em categorias. O paciente leva consigo a pasta para todos os locais. A pasta foi produzida com um pequeno conjunto de imagens, e adaptada ao longo do uso, onde pais e profissionais da instituição envolvida analisam as imagens mais utilizadas e compreendidas pelo paciente. Para as imagens que o paciente não entende, é necessário substituí-las por imagens que fazem parte do seu cotidiano. Neste caso, a melhor opção relatada pela responsável é a utilização de fotos.

Em caso de perda desta pasta, será necessário tempo e dinheiro para refazer o conteúdo, e durante este período a comunicação com o paciente será prejudicada. Além do problema de comunicação, alguns dos pacientes possuem problemas de concentração. Nesses casos, apresentar informações complexas pode ser uma tarefa difícil. Para a responsável, o fato do paciente não conseguir se comunicar é frustrante. Isso fez com que a responsável adaptasse a pasta de CAA do paciente com intuito de obter o melhor desempenho. Quando a imagem de um objeto referente à CAA pretendida não está na pasta de CAA, o paciente leva a pessoa responsável até o objeto de sua necessidade. A prioridade é aumentar a comunicação no contexto escolar e em casa, já que são os locais onde o paciente passa a maior parte do tempo.

De acordo com os fatos relatados nesta seção, verifica-se que a comunicação de pessoas com DI não ocorre da mesma forma de que as pessoas sem DI. A comunicação de pessoas com DI valoriza elementos mais específicos (como o som das palavras e imagem) e ocorre de uma forma mais simples e direta, algumas vezes até mesmo omitindo ou não levando em consideração elementos específicos de uma frase, como sujeito e verbo. Por fim chegamos a pergunta, quais os elementos que devem ser valorizados para que uma pessoa com deficiência de comunicação consiga se comunicar? Para responder essa pergunta, foi proposto um modelo de comunicação para pessoas com DI.

\subsection{Ciclo 2 do Design - Modelo de Comunicação Proposto}

Com base na teoria do ciclo anterior e uma pesquisa de literatura sobre modelos de comunicação, foi proposto um modelo de comunicação para pessoas com DI. Este modelo foi construído objetivando destacar determinados elementos de comunicação, os quais são necessários para que uma pessoa com DI possa se comunicar, ou entender uma comunicação. Dessa forma, nesta proposta de modelo a pessoa com DI pode atuar tanto como emissor quanto receptor em uma comunicação. O modelo de comunicação apresentado na Figura 1 é uma adaptação da proposta de Freixo (2006), o qual apresenta modelos de comunicação, conceitos sócios psicológicos e socioculturais, de diversos pesquisadores da área de comunicação. Esta adaptação se diferencia da apresentada por Freixo, primeiramente por se tratar de um modelo interpessoal de comunicação, e não de um modelo de massas; ter o foco em um emissor ou receptor, ou ainda ambos, com deficiência; utilização dos conceitos mais relevantes para esse público; e considerar limitações físicas e mentais como aspectos que podem influenciar a comunicação. É importante destacar que a comunicação de massa está subordinada ao gosto e a necessidade do público, e se apoia na realização de pesquisas para descobrir os fatores impactantes ao público (Beltrão and Quirino; 1986).

O trabalho de Silva et al. (2015) apresenta uma caracterização da Fabiana, uma mulher com 40 anos de idade, DI e com fala funcional. Adicionalmente o trabalho traz uma descrição de sua rotina, bem como suas necessidades e particularidades, por meio do uso da técnica de Personas. Este trabalho contribuiu para a realização do $1^{\circ}$ e $2^{\circ}$ ciclos de design. No presente trabalho, a proposta de modelo de comunicação apresentada na Figura 1, o emissor deve selecionar a mensagem a ser enviada. Essa mensagem contém a posição do emissor em relação a ela, de forma que seja simples, direta e coesa; para que o significado da mensagem enviada pelo emissor seja o mesmo entendido pelo receptor. A comunicação é determinada pelo emissor, de acordo com sua posição, status social, reputação e experiência. A posição em relação à mensagem influencia diretamente na sua estruturação, como por exemplo na escolha das figuras de linguagens, expressões e entonações. A autoimagem representa como o emissor compreende uma determinada mensagem e o significado que ele atribui a ela. Uma comunicação eficiente depende de adaptar as tentativas de intercomunicação à ocasião, à situação, ao tema e às pessoas envolvidas (Rosa and Landim; 2009).

A mensagem será codificada, transmitida por um meio eletrônico, e decodificada. Este é um conceito utilizado no Modelo de Comunicação Interpessoal de Schramm, onde tanto o emissor quanto receptor são capazes de codificar e decodificar a mensagem. Esta proposta utiliza o conceito de retroação, onde na medida em que se recebe uma mensagem ocorre uma reação de acordo com a mensagem recebida, contribuindo para haver um intercâmbio de influência na comunicação, exercidas entre si pelo emissor e receptor. Para Schramm, o ato de comunicação é interminável, sendo considerado por ele errado definir um início e um fim determinado. Esse modelo realiza uma transição do modelo linear para o cibernético (Freixo; 2006). Destaca-se que durante qualquer etapa do envio da mensagem, ela está sujeita a ruídos. O ruído é qualquer forma ou elemento interno ou externo que interfira, dificulte ou impeça o processo de transmissão da mensagem idealizado pelo emissor para o receptor. Existem 4 tipos de ruídos, são eles: físico, fisiológico, psicológico e semântico (da Educação; 2014).

O ruído físico se refere a qualquer barulho de origem externa, e que pode vir atrapalhar a comunicação. O ruído fisiológico é constituído por fatores que atrapalham o entendimento da mensagem pelo receptor e o impedem de raciocinar direito, por exemplo, dores de cabeça e de ouvido. Já no ruído psicológico, o receptor tenta entender a mensagem recebida, mas por algum motivo começa a pensar em outros assuntos não pertinentes ao momento, como uma falta de atenção. Ressalta-se que é normal a 


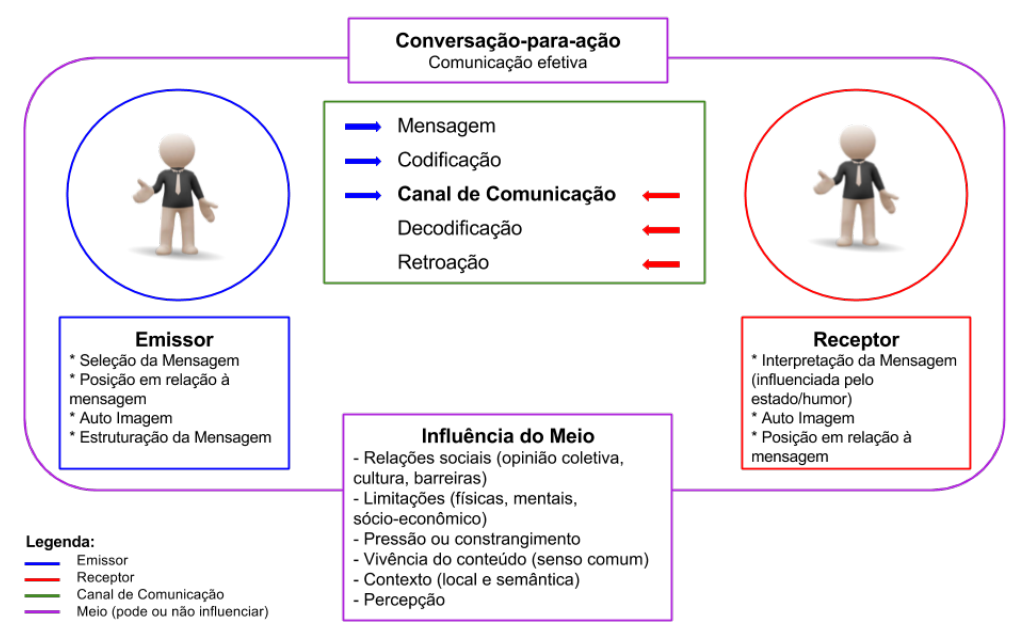

Figura 1: Modelo de Comunicação Adaptado

ocorrência de ruídos psicológicos. Eles podem ocorrer devido ao cansaço, excesso de trabalho, preocupação, entre outros, mas ao tornar-se rotineiro pode ter relação com déficit de atenção. O ruído semântico ocorre quando o receptor recebe uma mensagem, mas por algum motivo a interpreta de maneira diferente. Isso pode ocorrer quando uma mensagem tem muitos termos técnicos, gírias ou até mesmo frases com duplo sentido. Ao se comunicar com outra pessoa, independente do canal de comunicação utilizado, é necessário considerar o ruído durante a transmissão de uma mensagem, a fim de que o sentido idealizado para a mensagem pelo emissor seja o mesmo compreendido pelo receptor, ainda que com a presença do ruído.

Toda mensagem enviada gera uma retroação, uma breve inversão de papéis onde o receptor passa a ser um emissor por um curto período de tempo, e envia uma reação a mensagem recebida. Esse conceito de retorno de sentidos começou a ser utilizado a partir de 1980, sendo inicialmente introduzido nos contextos acadêmico e institucional (Araujo; 2004). Os interlocutores, tanto o emissor quanto o receptor, possuem uma posição em relação à mensagem. No caso do emissor, sua posição influenciará no momento da construção da mensagem, onde o emissor seleciona a mensagem a ser transmitida a partir do seu ponto de vista de acordo com a sua percepção. A percepção é a forma de um interlocutor interpretar e compreender as ações realizadas (seu ponto de vista único sobre uma determinada situação) (Tedesco et al.; 2012). Desta forma, o posicionamento em relação à mensagem decidirá a forma como ela será construída, enfatizada e até mesmo o tipo de comunicação que será estabelecida de acordo com sua percepção. Ainda é importante destacar que nesta etapa é necessário haver um conhecimento compartilhado, para que tanto os sinais como significado da comunicação sejam compreendidos; esse conhecimento é denominado senso comum (Vivacqua and Garcia; 2012).

O receptor por sua vez irá interpretar a mensagem e criar sua posição em relação a ela. A forma de interpretação pode ser influenciada por alguns fatores. Como por exemplo, a percepção do receptor em relação a mensagem, a forma como o receptor acredita que o emissor se posicionou (nem sempre é a real), até o humor do próprio receptor pode influenciar no entendimento da mensagem. Esses são alguns fatores que podem influenciar na retroação, podendo o receptor mostrar sua satisfação com a mensagem, bem como suas contribuições ou novas requisições (Winograd; 1986). Além disso, o processo inverso deve ser considerado, quando o receptor não se mostra satisfeito com a forma em que ele percebeu a mensagem.

Existem outros fatores que podem influenciar no entendimento, para denominar esses fatores será utilizado o termo: Influência do Meio. A Influência do Meio é visto como um fator que pode ter grande ou pouca influência na realização de um diálogo, uma vez que o meio pode influenciar de maneira indireta. Por exemplo, em um diálogo entre 2 amigos onde ambos estão inseridos da mesma forma no mesmo contexto. O contexto faz com que a mensagem transmitida seja mais efetiva, uma vez que o contexto influencia na forma como a mensagem é compreendida (Tedesco et al.; 2012). De acordo com Jannuzzi and Tálamo (2004), a comunicação propicia a transmissão de informações, utilizando-se noções abstratas provenientes das experiências vivenciadas por cada indivíduo, provenientes do conhecimento adquirido pelo indivíduo ao longo de sua vida.

Além disso, o contexto pode determinar os rumos de uma comunicação, visto que o meio faz parte da formação do indivíduo, assim como as suas relações sociais (opinião da comunidade, a cultura que os interlocutores estão inseridos e as barreiras sociais). $O$ contexto influencia na interpretação e percepção da mensagem. Além disso, os usuários que partilham do mesmo contexto possuem mais facilidade de interpretação de mensagem, quando comparados com usuários de contextos diferentes (Tedesco et al.; 2012). O contexto também é considerado um instrumento de apoio da comunicação, diminuindo a ambiguidade e aumentando a expressividade, atuando antecipadamente como um emissor de uma mensagem conhecida ou codificada.

Outro ponto que precisa ser levado em consideração diz respeito às frases que podem causar pressão ou constrangimento conforme a cultura de uma determinada sociedade. As limitações 
físicas, mentais e sócio econômicas, podem estar presentes com menor ou maior grau de intensidade, independente da sociedade. Por meio da vivência desses fatores, o indivíduo cria a sua percepção. Já os mecanismos de percepção "são técnicas empregadas em um sistema para oferecer informações que apoiem a percepção dos usuários" (Tedesco et al.; 2012). Contexto e momento também podem influenciar a posição em relação a mensagem, status, reputação e experiências, em uma comunicação (Rosa and Landim; 2009).

Destaca-se o conceito de comunicabilidade no meio de transmissão e utilização da Engenharia Semiótica. Não basta que o projetista elabore um bom sistema, o sistema deve ser capaz de apresentar possibilidades de interação, de forma que os usuários possam explorar o máximo do seu potencial (Prates; 2012). Ao final deste ciclo a terapeuta e fonoaudióloga desenharam um protótipo de baixa fidelidade de itens que deveria estar no aplicativo de CAA.

\subsection{Ciclo 3 do Design - Modelo de Comunicação e Aplicativo}

Após o desenvolvimento da proposta de modelo de comunicação foram desenvolvidos os protótipos de aplicativo de forma minimalista, objetivando a simplicidade e facilidade de uso. O protótipo é composto dos elementos de comunicação levantados no modelo de comunicação proposto. O terceiro ciclo de desenvolvimento consiste no planejamento, desenvolvimento e avaliação do modelo físico, tendo como base os ciclos anteriores e o Design Participativo, forma de workshop e protótipos de alta fidelidade. Este ciclo tem a finalidade de avaliar se os protótipos idealizados pelo autor atendem as necessidades dos usuários. Nesta primeira etapa de protótipos, as telas foram idealizadas buscando sua funcionalidade, e o menor número de componentes na tela. Dessa forma, os protótipos foram idealizados de forma a possuir as funções necessárias para a utilização da CAA. As telas foram construídas para serem semelhantes, alterando somente as imagens de CAA exibidas, a fim de reduzir o tempo de aprendizado; são automatizadas, de forma que ao selecionar um sujeito, o aplicativo automaticamente exibe as ações disponíveis àquele sujeito. Outra funcionalidade do sistema, é que a cada imagem clicada o sintetizador reproduz o texto abaixo da imagem. Já a opção de ouvir a frase completa montada será reproduzida quando a opção de reprodução do som for selecionada. A Figura 2 exibe como o modelo de comunicação influenciou no desenvolvimento dos protótipos de aplicativo.

Os protótipos foram idealizados com elementos necessários à comunicação, e que possuísse alguma finalidade de acordo com o modelo de comunicação. De acordo com a Figura 2, os elementos do modelo de comunicação podem ser identificados no aplicativo, como:

- A posição de um emissor em relação a mensagem é representada pelos sujeitos (eu, você, eu quero, entre outros), que são utilizados para expressar o desejo ou necessidade de algo;

- A estruturação da mensagem é representada pela ordem de apresentação da CAA (sujeito + ação
+ opção de ação), pelo botão apagar e a caixa de exibição da frase selecionada. Ressalta-se que durante um diálogo, nem sempre o usuário consegue elaborar a comunicação pretendida, dessa forma, organizar a comunicação de forma que exija menos trabalho pode facilitar sua utilização;

- A autoimagem é encontrada no campo de estruturação da mensagem, no campo de seleção da mensagem e no ícone para reproduzir a mensagem selecionada. Ela precisa ser constantemente reforçada, uma vez que a autoimagem influencia na interpretação da comunicação, levando em consideração a maneira de como o usuário interpreta o ambiente, e na escolha das expressões;

- A seleção de mensagem é representada pelas imagens de comunicação exibidas na tela, e pelo botão "Não Sei", uma vez que o sistema possui um conjunto de comunicação finita, e a expressão pretendida pode não estar disponível naquele momento ao usuário;

- As limitações estão relacionadas principalmente com o tamanho das imagens; a compreensão delas; a alfabetização do usuário (para leitura das legendas nas imagens); a velocidade de pronúncia das palavras pelo sintetizador de voz; a capacidade de entendimento do usuário por meio do sintetizador e a capacidade do usuário na utilização do tablet;

- Por fim, relações sociais, pressão, vivência, contexto e percepções, tornam-se diretrizes para a seleção das imagens. O aplicativo desenvolvido é apresentado na Figura 3. O aplicativo possui 5 funcionalidades: (1) campo retangular destinado para a exibição das imagens de comunicação selecionadas, (2) um botão para apagar mensagens selecionadas, (3) um botão para ouvir a mensagem, (4) uma área de tela com imagens de CAA para selecionar e a (5) funcionalidade "Não sei". A opção "Não sei" foi idealizada para quando a opção de comunicação desejada não estiver disponível.

Uma das técnicas do Design Participativo consiste em mostrar os protótipos ao usuário final para serem avaliados. Nesta etapa, o protótipo mostrado na Figura 3, apresenta uma tela onde sujeito e ação já foram selecionados nas telas anteriores, restando a seleção de opções de ação. As telas foram avaliadas por uma terapeuta e uma fonoaudióloga, por meio da apresentação de protótipos de alta fidelidade durante os workshops. Como retorno positivo, três pontos foram destacados: primeiro foi design minimalista das telas, apresentando uma interface limpa; telas semelhantes; e a presença do botão para reproduzir o som da comunicação. De acordo com as profissionais da instituição, a reprodução de som é uma etapa muito importante para compreender e aprender a comunicação, uma vez que a comunicação oral é a mais utilizada no dia a dia. Foram destacados dois pontos negativos: o primeiro é que o paciente raramente utiliza a opção "Eu", e sim uma opção "Eu Quero"; o segundo ponto é que a imagem utilizada para a opção "Eu" normalmente possui como representação uma foto da pessoa que está utilizando a CAA. Os protótipos foram elaborados de acordo com a pasta de PCS do paciente da instituição. Por questões de direitos autorais, foram utilizadas 


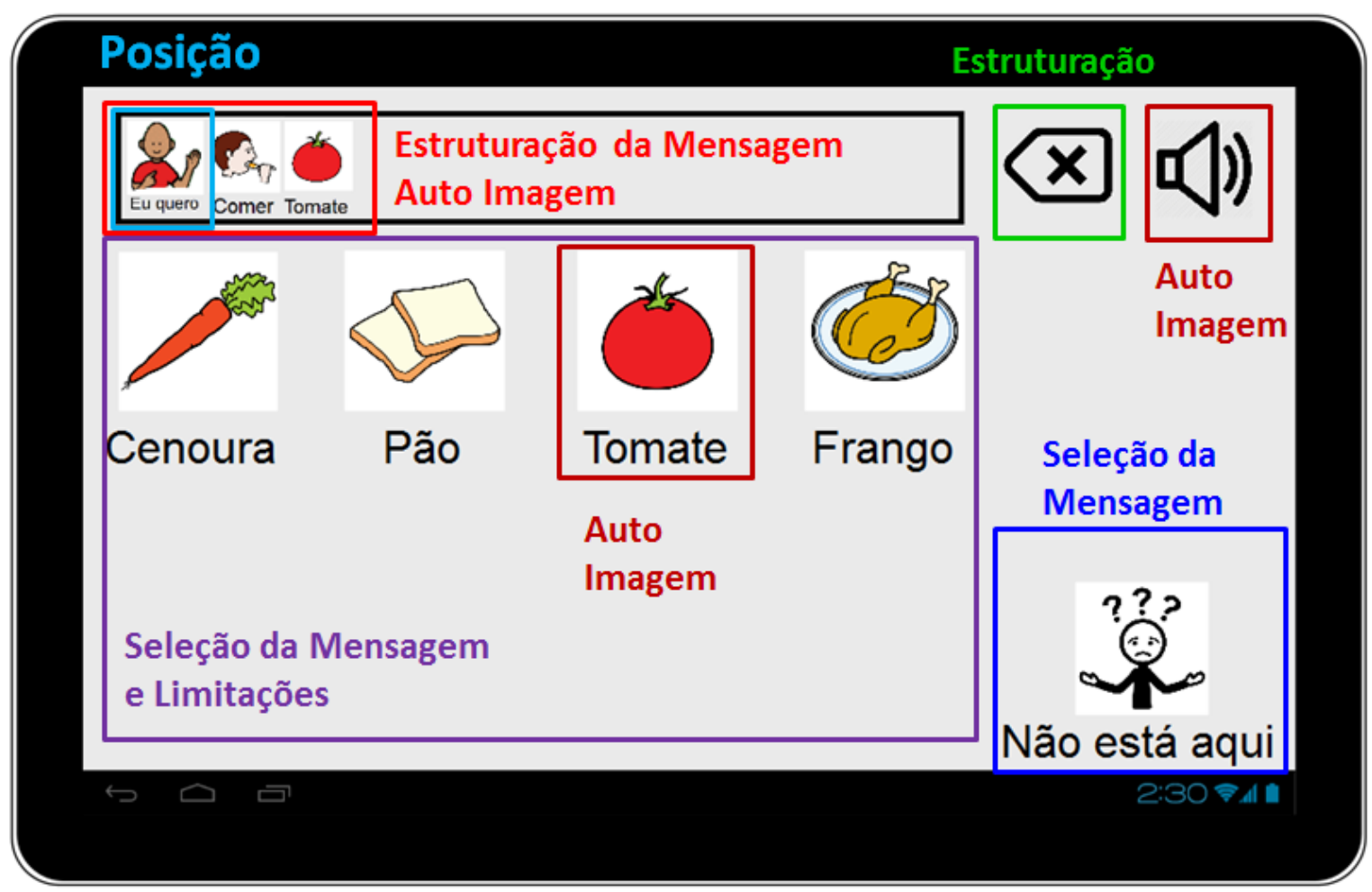

Figura 2: Modelo de Comunicação do Protótipo

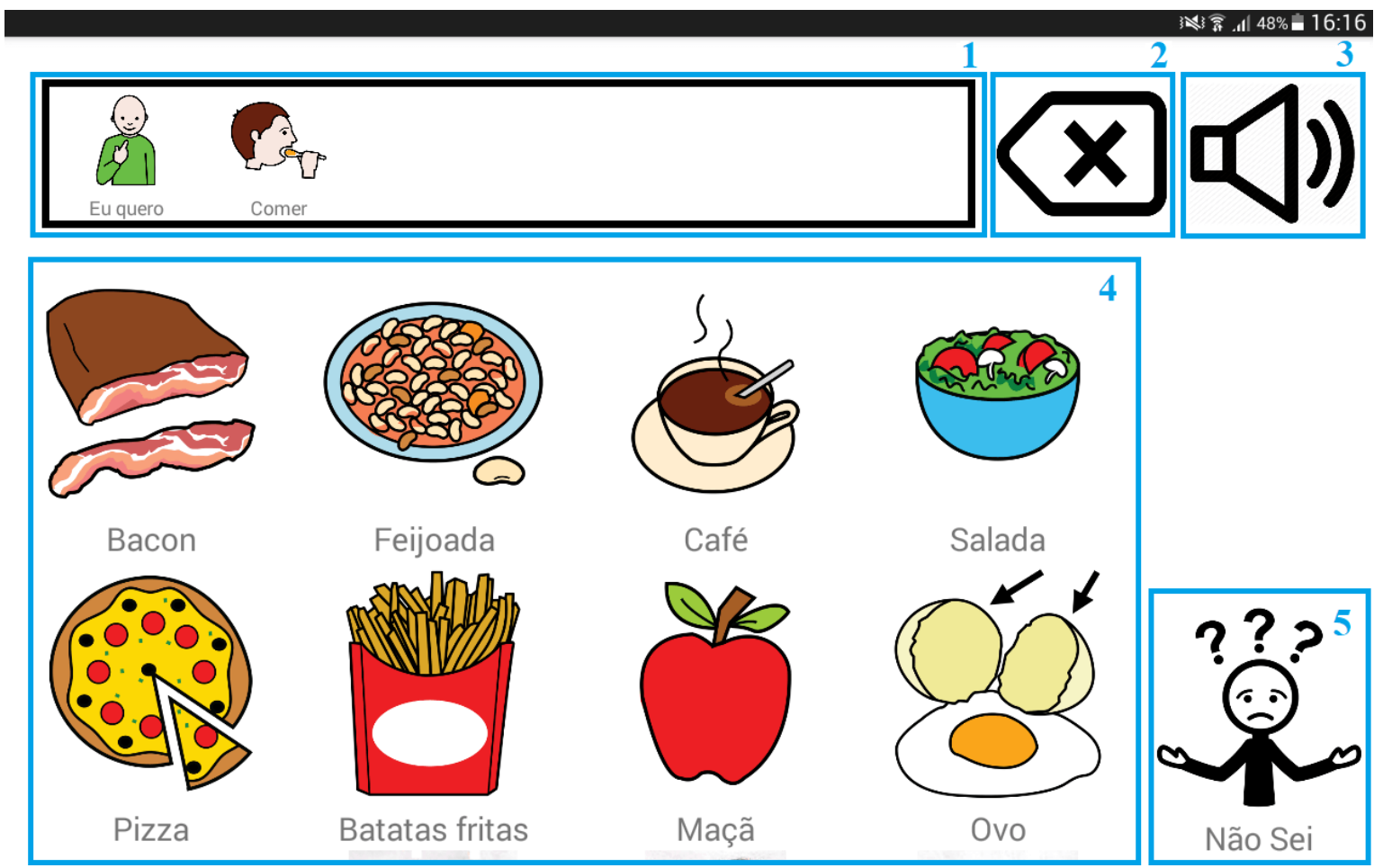

Figura 3: Apresentação do Aplicativo 
imagens iguais ou semelhantes a partir de um repositório online (Palao; 1994), o qual permite sua livre utilização e compartilhamento, exceto para fins comerciais. Para preservar a identidade do participante, foram omitidas imagens nos protótipos as quais poderiam ser usadas para identificá-lo.

\subsection{Rigor da Pesquisa}

Antes de declarar que um software está pronto para uso, é importante saber se ele apoia adequadamente os usuários no ambiente que será utilizado (Prates and Barbosa; 2003). Dessa forma, no primeiro ciclo do DSR foi gerado o conhecimento base, para dar início ao DSR e ser o suporte aos demais ciclos realizados de DP (Rocha et al.; 2015). Dentre os métodos do DP, foi utilizado o método de Workshop em todos os ciclos de design do DSR, para acompanhar o desenvolvimento e desempenho do aplicativo; e protótipos de alta fidelidade no terceiro ciclo.

A primeira iteração do ciclo de design foi realizada em duas partes, sendo: a primeira etapa, caracterizada por um estudo de campo por meio de reuniões e observação do usuário, o objetivo foi compreender a realidade de uma pessoa com deficiência de comunicação, em conjunto com as necessidades enfrentadas no dia a dia; a segunda etapa consistiu de uma busca na literatura por trabalhos correlatos.

Após o conhecimento do público foi necessário conceituar como ocorre a comunicação, quais os fatores que devem ser levados em consideração para estabelecer uma comunicação. Diversos públicos podem ter deficiências de comunicação (Falcão and Price; 2012), dessa forma, estabelecer um padrão único ou diversos padrões para serem utilizados com os mais diversos públicos, torna-se uma tarefa desafiadora. Nesse contexto entra a comunicação de massas. Essa comunicação tem por finalidade estabelecer a comunicação com todos os membros de uma sociedade (Mcquail et al.; 2003), se mostrando promissora para o desenvolvimento da pesquisa.

$O$ terceiro ciclo se caracterizou pelo desenvolvimento e avaliação dos protótipos de telas, desenvolvidos com base no segundo ciclo. A análise foi realizada por dois profissionais da instituição estudada, os quais estão habituados com as necessidades dos pacientes que frequentam o instituto, e possuem experiência em se comunicar com pessoas com problemas de comunicação. A avaliação da interface é necessária para realizar a avaliação da qualidade de uso de um software Rocha and Baranauskas (2003). Ainda, a avaliação formativa procura melhorar a interface, por meio de avaliações de pontos negativos e positivos, durante 0 design iterativo Nielsen (1994).

\section{Resultados}

Nesta seção são detalhados os resultados encontrados neste trabalho. Durante os testes é realizado a construção do conjunto de imagens de CAA, e uma análise qualitativa de uso do aplicativo, por meio de workshop, durante o cotidiano. As datas disponibilizadas para as interações foram 17/04/17 e 20/04/17; conforme a disponibilidade do Núcleo de
Atendimento Integral ao Paciente Especial (NAIPE).

\subsection{Testes com o Usuário}

Para a primeira interação foram utilizadas imagens com base na pasta de Picture Communication System (PCS), que o usuário já possuía. Foram realizadas 2 interações no instituto NAIPE, os resultados são apresentados conforme a ordem em que foram realizados. Cada interação possuía um limite de 50 minutos, e acompanhada pelo responsável do paciente, e pelo menos um profissional (terapeuta ocupacional ou fonoaudióloga). A Figura 4 mostra o aplicativo de comunicação sendo utilizado por "João (nome fictício)" durante os testes. Nesta interação foi realizada uma apresentação do aplicativo para o paciente. $O$ paciente pode ter um tempo livre para exploração da ferramenta, bem como obter instruções sobre o seu funcionamento. O tempo livre foi necessário para fazer com que o paciente se sentisse seguro com o uso da nova comunicação, e principalmente para fornecer a oportunidade de adaptação ao uso do aplicativo e dar a oportunidade de incorporar o aplicativo ao seu cotidiano.

O processo de ensino foi realizado após o paciente estar habituado ao uso do aplicativo. Esse tempo pode variar para cada pessoa. Neste trabalho, o paciente apresentou um bom desenvolvimento para uso do dispositivo tablet, bem como para o uso do aplicativo de CAA. Foram necessários 10 minutos para que o paciente entendesse os comandos do aplicativo e 30 minutos para ensiná-lo a utilizar a ferramenta. O primeiro conjunto de imagens estava relacionado com o cotidiano do paciente, contendo imagens para alimentação, higiene, escola, vestuário e respostas básicas (sim, não, desculpa, obrigado, etc). Na segunda interação foi realizada uma entrevista com a sua mãe para verificar como foi o uso do aplicativo, após realizada atualizações do conjunto de CAA disponível para o paciente. A mãe relata que o filho inicialmente buscava o tablet para se comunicar, porém, como o tablet não possuía todas as imagens de comunicação que o João estava acostumado, João buscava pasta PCS para se comunicar. A mãe classificou que a comunicação do tablet foi boa, inclusive o João utilizou o tablet para realizar o pedido de um Milk-shake em uma sorveteria, e o atendente compreendeu a sua requisição. A mãe relata que o ato do atendente compreender o pedido de forma rápida, não havia sido realizado antes com o uso da pasta PCS. Também é relatado que algumas imagens não foram compreendidas sem a reprodução do nome dela, e algumas precisaram ser substituídas por fotos.

Posteriormente também foi relatado que o paciente utilizou o tablet para se comunicar com seus avós. Segundo a mãe, os avós não conseguiam entender bem a pasta de comunicação, porém, com o sintetizador de voz do tablet permitiu estabelecer o diálogo de forma efetiva, onde os avós entenderam o que o paciente queria comunicar. Durante a primeira e segunda interação também é relatado a curiosidade do paciente na exploração das imagens, bem como o aprendizado delas. A forma de organização de imagens (Sujeito, Ação e Opção de Ação) permitiu explorar outras combinações de organizações de grupos de imagens, como o grupo "Escola", composto 


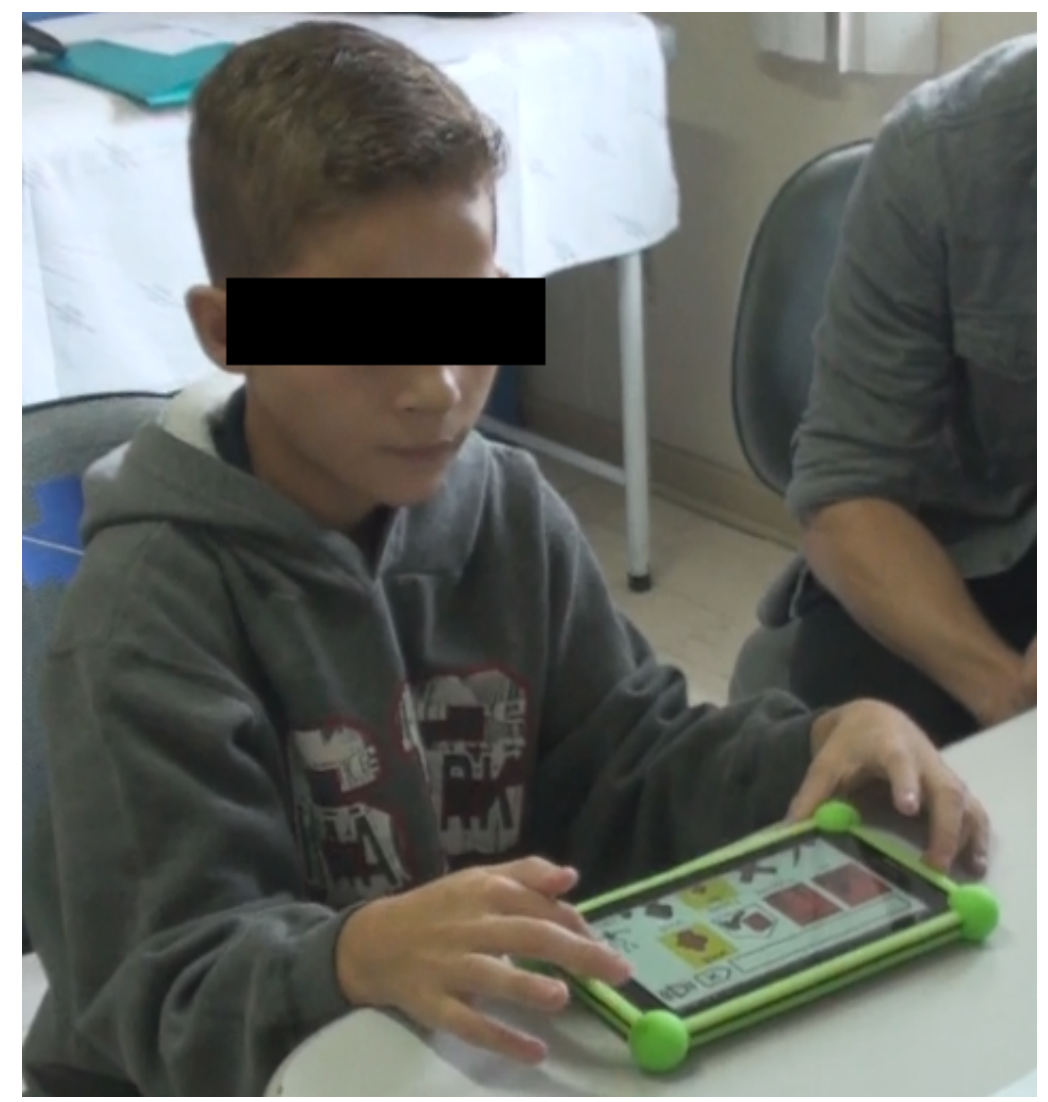

Figura 4: João utilizando o aplicativo de comunicação

pelos subgrupos de imagens: Materiais, Animais, Alfabeto, Cores, Números, entre outros. Neste ponto é relatado pela mãe que a proposta de aplicativo baseada no modelo de comunicação proposto, se mostrou: adaptável tanto para uma comunicação mais formal (empregando o uso de sujeitos), quanto para uma comunicação mais rápida; mantendo a coerência da mensagem em ambos os casos; e sem prejudicar sua forma de uso idealizada no aplicativo. João está sendo capaz de completar mais diálogos. Também é relatado duas alterações de comportamento em João: ele obteve mais iniciativas de comunicação, em casa e fora dela; diminuiu seu nervosismo, de acordo com a mãe, João fica muito irritado quando não consegue se comunicar com as pessoas, após iniciar o uso do aplicativo de CAA esse nervosismo dele vem diminuindo gradativamente.

\subsection{Resultados}

Com a participação dos profissionais da instituição (terapeuta ocupacional e fonoaudióloga) em conjunto com a mãe, foram avaliados os protótipos elaborados. Também foi possível compreender algumas das principais necessidades da pessoa com deficiência intelectual, durante o uso da CAA em conjunto com tablet. As necessidades identificadas estão descritas a seguir:

- Necessidade de personalização de figuras ou imagens, uma vez que elas podem ser subjetivas conforme a região onde o usuário está localizado; - Explorar o significado por meio de imagem, texto e som; utilizar mais de uma forma de comunicação e diminuir as restrições, exibindo uma comunicação atrativa e fácil de utilizar e explorando o significado dos signos. O uso de diferentes formas de apresentação de informação é uma das diretrizes do Design Universal (Almeida and Baranauskas; 2010).

- Adaptar o número e tamanho de componentes na tela. Algumas pessoas podem ter problemas acentuados de coordenação motora, em alguns casos há a necessidade de aumentar do tamanho de imagens e textos;

- Manter consistência no posicionamento de imagens, a tela não pode sofrer muitas alterações (como alteração no layout e posicionamento de imagens), o que pode atrapalhar a memorização e capacidade de aprendizagem do aplicativo;

- Separação por categorias de imagens, de acordo com ações que o usuário tem autonomia para realizar (categoria "Eu" e "Eu quero"), e as categorias as quais o usuário precisa de ajuda (categoria "Você"), facilitando a organização e diminuindo o número de imagens apresentada por tela;

- Facilitar e automatizar o uso do aplicativo, por exemplo, se o usuário deletou a última imagem selecionada deve-se voltar a sessão anterior, e ao selecionar uma imagem $\mathrm{X}$, exibir automaticamente o próximo grupo de imagens pertencentes a $\mathrm{X}$, tornando o aplicativo mais automatizado;

- A questão da autoimagem deve ser reforçada, a fim de que a pessoa com deficiência de comunicação, compreenda a forma como a comunicação é 
realizada, e possa se "fazer entender" ao público.

É relatado pela mãe de João, que ele conseguiu concretizar mais comunicações utilizando o tablet quando comparado com o uso da Pasta PCS. Ela também destacou o pedido de Milk-shake, por ter sido realizado pela primeira vez, e ocorrido em um ambiente não comum ao cotidiano João. Também é destacado uma alteração de comportamento, diminuindo a sua ansiedade e comportamento agressivo.

\section{Discussões}

Durante a construção e avaliação de telas com o design participativo, é levantado o ponto que uma interface com menos componentes pode ter um resultado melhor. Uma interface ideal deve possuir um número reduzido opções disponíveis, evitar elementos que possam confundir em vez de ajudar, ou até mesmo distrair o usuário. A automatização de telas é vista como um aspecto facilitador, neste caso, ao selecionar um determinado sujeito, automaticamente o aplicativo passa para a tela com as ações disponíveis para o sujeito selecionado. Um dos conceitos apresentados pelos profissionais da instituição foi a necessidade de uma estrutura de frases mais próxima da linguagem do dia a dia, seguindo uma estrutura de: Sujeito + Ação + Opção de Ação. Embora sistemas de comunicação que possuem um conjunto reduzido de signos, ou que permitam a abreviação e respostas rápidas, podem fazer com que a comunicação não fique clara a qualquer ouvinte ou não ser a mais adequada. A comunicação é particular de cada pessoa, mas a estrutura Sujeito + Ação + Opção de Ação, é comum para a construção de frases. Essa estrutura facilita a construção do entendimento de uma frase, além de ser mais semelhante à comunicação praticada no dia a dia.

Quanto a imagem dos sujeitos utilizados, sempre que possível é adequado usar imagens que possuam significados, como foto do usuário, fotos dos membros da família, bem como expressões curtas e regularmente utilizadas, como: sim, não e me ajuda. Nem todas as frases precisam de um sujeito, para algumas respostas um sim ou não já basta. Deve-se levar em consideração a possibilidade de a pessoa com deficiência querer comunicar algo, mas não saber como expressar ou quais palavras utilizar. De acordo com as profissionais da instituição, é indicado que a escolha de ação, preferencialmente deve ser particular a cada sujeito. Ou seja, sujeitos que indiquem primeira pessoa deve ser relacionado a ações que aquele usuário tenha autonomia para desempenhar. Já sujeitos que indiquem segunda e terceira pessoa devem conter ações que o usuário necessite de alguma ajuda ou outra pessoa para desempenhar.

Também é destacado pelas profissionais da instituição, que a utilização do som terá efeito de reforço para que o usuário assimile imagens ao seu som, e a escrita. A utilização apenas da comunicação oral é muito comum no dia a dia, em casos onde não é possível realizar uma comunicação só oral, é utilizado outras formas de comunicação (como o uso de imagens e gestos) para tentar efetivar o diálogo. Embora o aplicativo desenvolvido almejava a comunicação, é destacado que o João também usou o aplicativo para fins didáticos durante os testes, na forma de: copiar as legendas das imagens de CAA, e usar a categoria de imagens de alfabeto para escrever palavras.

\section{Conclusões}

Este trabalho tem por finalidade identificar como a Comunicação Aumentativa e Alternativa (CAA) pode apoiar pessoas com Deficiência Intelectual (DI) a se comunicarem, por meio do uso de dispositivos móveis. Para alcançar os objetivos foi utilizado o framework conceitual Design Science Research (DSR) em conjunto com o Design Participativo (DP). O DP foi utilizado durante todos os ciclos de design do DSR. O DSR propiciou o desenvolvimento da pesquisa de forma incremental, e o DP forneceu uma visão e compreensão do problema do ponto de vista do usuário. Essas duas formas de pesquisa se mostraram eficientes ao trabalhar em conjunto, o DP proporcionou conhecimento diferenciado a respeito do problema, e a documentação gerada no processo de solução do DSR ajudou na tomada de decisões de rumos do projeto. Com a participação dos profissionais da instituição (terapeuta ocupacional e fonoaudióloga), em conjunto com a responsável (mãe), foi avaliado o modelo de comunicação proposto, bem como os protótipos elaborados. De acordo com os resultados dos testes, foi possível caracterizar o usuário com DI, adaptar um modelo de comunicação e testar os protótipos funcionais de telas, no sentido de gerar uma comunicação efetiva. Também foi possível identificar algumas das necessidades para utilização da CAA com dispositivos móveis, tais como: personalização da CAA, separação por categorias de autonomia e explorar o significado por mais de um canal de comunicação (como imagem, texto e som).

Por fim, destaca-se que a tecnologia tem potencial para apoiar o diálogo de pessoas com DI. Porém, é necessário instigar a pessoa que usará a comunicação até o ponto em que ela se aproprie tanto do aplicativo de CAA quanto do dispositivo que está sendo utilizado. Também é importante que o aplicativo de CAA esteja personalizado com as imagens de CAA que representem um significado para o usuário, caso contrário o usuário não irá entender nem utilizar. É importante ressaltar que a comunicação é constitutiva de cada pessoa. Cada indivíduo adota sua expressão de linguagem de modo a possuir sua identidade e significados próprios. Como próximos passos, pretende-se: trabalhar com a comunicação gravada pelos responsáveis, e não um sintetizador de voz; e adicionar um módulo para digitação de textos com leitura por meio do sintetizador de voz.

\section{Colaboradores}

Agradecimentos ao João, sua mãe, e ao NAIPE, em especial suas profissionais: terapeuta ocupacional Luciana Correa e fonoaudióloga Tatiane Dominoni Rodrigues. 


\section{Referências}

Almeida, L. D. A. and Baranauskas, M. C. C. (2010). Universal design principles combined with web accessibility guidelines: a case study, Proceedings of the IX Symposium on Human Factors in Computing Systems, Brazilian Computer Society, pp. 169-178.

Araujo, I. S. (2004). Mercado simbólico: um modelo de comunicação para políticas públicas, Interface (Botucatu) 8(14). http://dx.doi.org/10. 1590/S1414-32832004000100010.

ASSOCIATION, A. P. (ed.) (2014). DSM-5: Manual diagnóstico e estatístico de transtornos mentais., Artmed Editora, Porto Alegre, PR, BR.

Beltrão, L. and Quirino, N. O. (eds) (1986). Subsídios para uma teoria da comunicação de massa., Summus Editorial, São Paulo, SP, BR.

Black, R., Waller, A., Turner, R. and Reiter, E. (2012). Supporting personal narrative for children with complex communication needs., ACM Transactions on Computer-Human Interaction (TOCHI) 19(2): 15. http://dx.doi.org/10.1145/2240156.2240163.

Bonifácio, B., Viana, D., Vieira, S., Araujo, C. and Conte, T. (2010). Aplicando técnicas de inspeção de usabilidade para avaliar aplicações móveis, in B. C. Society (ed.), Proceedings of the IX Symposium on Human Factors in Computing Systems, pp. 189-192.

Caran, G. M., Santini, R. M. and Biolchini, J. C. A. (2016). Use of social network to support visually impaired people: A facebook case study, Transinformação 28(2): 173-180. http://dx. doi.org/ 10.1590/2318-08892016000200004.

Carniel, A., Berkenbrock, C. and Hounsell, $M$. (2017). Um mapeamento sistemático sobre o uso da comunicação aumentativa alternativa apoiada por recursos tecnológicos, Revista Brasileira de Computação Aplicada 9(2): 84-98. https://doi.org/ $10.5335 /$ rbca.v9i2.6500.

Carvalho, E. N. S. and Maciel, D. M. M. A. (2003). Nova concepção de deficiência mental segundo a american association on mental retardation-aamr: sistema 2002, Temas em Psicologia 11(2): 147-156.

da Educação, P. (ed.) (2014). Exemplos de Ruídos na Comunicação. Disponível em http://www. portaleducacao.com.br/marketing/ artigos/53332/exemplos-de-ruidos-na-comunicacao (Accessado 29 Outubro 2017).

Falcão, T. P. and Price, S. (2012). Tangibles for students with intellectual disabilities, in ACM (ed.), Proceedings of the 11th International Conference on Interaction Design and Children, pp. 371-374.

Farias, M. G. G. (2016). A informação como potencializadora da autonomia e da integração social, Transinformação 28(3): 323-336. http://dx. doi.org/10.1590/2318-08892016000300007.

Freixo, M. J. V. (ed.) (2006). Teorias e modelos de comunicação, Instituto Piaget.

Hevner, A. R. (2007). A three cycle view of design science research, Scandinavian Journal of Information Systems pp. 87-92.
Hevner, A. R., March, S. T., Park, J. and Ram, S. (2004). Design science in information systems research, MIS Q. 28(1): 75-105. Disponível em http: //dl . acm.org/citation. cfm?id=2017212.2017217 (Accessado 29 Outubro 2017).

Hong, E. R., Ganz, J. B., Neely, L., Gerow, S. and Ninci, J. (2014). A review of the quality of primary caregiver-implemented communication intervention research for children with asd, Research in Autism Spectrum Disorders 8(5): 570-580. https://doi.org/10.1016/j.rasd.2016.02.005.

Huijbregts, T. and Wallace, J. R. (2015). Talkingtiles: supporting personalization and customization in an aac app for individuals with aphasia, Proceedings of the 2015 International Conference on Interactive Tabletops \& Surfaces, ACM, pp. 63-72.

Jannuzzi, C. A. S. C. and Tálamo, M. F. G. M. (2004). A empresa e os sistemas humanos de informação: uma abordagem conceitual para a gestão de informação, Transinformação 16(2): 171187.

Mantoan, M. T. E. (1994). Ser ou estar, eis a questão: uma tentativa de explicar o que significa o déficit intelectual, Pró-posições 5(2): 60-68.

Mcquail, D., De Jesus, C. and Ponte, C. (eds) (2003). Teoria da comunicação de massas, Fundação Calouste Gulbenkian.

Melo, A. M. (2014). Acessibilidade e inclusão digital, in SBC (ed.), Livro dos Tutoriais do XIII Simpósio Brasileiro sobre Fatores Humanos em Sistemas Computacionais, pp. 29-54.

Moreschi, C. L. and Almeida, M. A. (2012). A comunicação alternativa como procedimento de desenvolvimento de habilidades comunicativas, Revista Bras Ed Esp 18(4): 661-76. http://dx.doi. org/10.1590/S1413-65382012000400009.

Nielsen, J. (ed.) (1994). Usability engineering, Elsevier.

Palao, S. (ed.) (1994). ARASAAC - Aragonese Portal of Augmentative and Alternative Communication.

Pinheiro, A. and Neris, V. P. A. (2013). Uma revisão sistemática sobre tecnologias de informação e comunicação aplicadas às práticas de sustentabilidade, in B. C. Society (ed.), Proceedings of the 12th Brazilian Symposium on Human Factors in Computing Systems, pp. 339-340.

Prates, R. O. (2012). Interação em sistemas colaborativos. In Sistemas Colaborativos, Elsevier Editora Ltda.

Prates, R. O. and Barbosa, S. D. J. (2003). Avaliação de interfaces de usuário-conceitos e métodos, in SBC (ed.), Jornada de Atualização em Informática do Congresso da Sociedade Brasileira de Computação, pp. 29-54.

Reis, B. F. (2016). Análise cromossômica por microarray em pacientes com deficiência intelectual associada à obesidade, Universidade de Brasília . http://dx.doi.org/10.26512/2015.12.D. 19254. 
Rocha, E. B., Pimentel, M., Diniz, M. C. and Santoro, F. M. (2015). Design science research para o desenvolvimento de um modelo da participação em bate-papo, ISYS, Revista Brasileira de Sistemas 8(1): 18-41. Disponível em http://www. seer. unirio. br/index.php/isys/article/view/4342 (Acessado em 29 Outubro 2017).

Rocha, H. V. and Baranauskas, M. C. C. (2003). Design e avaliação de interfaces humano-computador, Unicamp, São Paulo, SP, BR.

Rogers, Y., Sharp, H. and Preece, J. (eds) (2007). Wiley.

Rosa, A. S. and Landim, D. C. B. (2009). Comunicação: a ferramenta do profissional, Perquirere-Revista do Núcleo Interdisciplinar de Pesquisa e Extensão do Unipam pp. 141-155. Disponível em http:// perquirere.unipam.edu.br/documents/23456/35660/ Comunicacao_a_ferramenta_do_profissional.pdf (Acessado 29 Outubro 2017).

Silva, D. M. A. d., Sartori, D. F., Gasparini, I. and Berkenbrock, C. D. M. (2015). Utilizando design centrado no usuário para definição de um sistema colaborativo de monitoramento geográfico para pessoas com deficiência intelectual, XII Simpósio Brasileiro de Sistemas Colaborativos (SBSC) pp. 71-77.

Still, K., May, R. J., Rehfeldt, R. A., Whelan, R. and Dymond, S. (2015). Facilitating derived requesting skills with a touchscreen tablet computer for children with autism spectrum disorder, Research in Autism Spectrum Disorders 19: 44-58. http://dx. doi.org/10.1016/j.rasd.2015.04.006.

Tania, D., Mumford, L., Hotze, F. and Chau, T. (2014). Implementing an ipad-based alternative communication device for a student with cerebral palsy and autism in the classroom via an access technology delivery protocol, Computers \& Education 79: 148-158. https://doi.org/10.1016/j.compedu. 2014.07.009.

Tedesco, P., Dos Santos, V. V. and Salgado, A. C. (2012). Capítulo 10 - Percepção e contexto. In Sistemas Colaborativos, Elsevier Editora Ltda.

Tomas, R. V. V., Rosa, T. L., Van, D. B. and Melo, D. G. (2016). Políticas públicas de saúde para deficientes intelectuais no brasil: uma revisão integrativa., Ciênc. saúde coletiva 21(1): 155-172. http://dx.doi. org/10.1590/1413-81232015211.19402014.

Vaishnavi, V. and Kuechler, W. (2004). Design research in information systems, Elsevier Editora Ltda.

Vivacqua, A. S. and Garcia, A. C. B. (2012). Capítulo 3 ontologia de colaboração. in sistemas colaborativos, Elsevier Editora Ltda pp. 34-49.

Waller, A., Black, R., O'Mara, D. A., Pain, H., Ritchie, G. and Manurung, R. (2009). Evaluating the standup pun generating software with children with cerebral palsy, ACM Transactions on Accessible Computing (TACCESS) p. 16. http://dx.doi.org/10. 1145/1497302.1497306.

Wheeler, M., Wolf, F. and Kyber, R. (2013). Supporting augmented and alternative communication using a low-cost gestural device, Proceedings of the 15th International ACM SIGACCESS Conference on Computers and Accessibility, ACM, Bellevue, Washington, USA. http://dx.doi.org/10.1145/2513383.2513386.

Winograd, T. (1986). A language/action perspective on the design of cooperative work, Proceedings of the 1986 ACM Conference on Computer-supported Cooperative Work, ACM, Austin, Texas, USA, pp. 203220. http://doi . acm.org/10.1145/637069.637096. 